\title{
Selective blood-nerve barrier leakiness with claudin-1 and vessel-associated macrophage loss in diabetic polyneuropathy
}

\author{
Adel Ben-Kraiem ${ }^{1} \cdot$ Reine-Solange Sauer ${ }^{1} \cdot$ Carla Norwig $^{1} \cdot$ Maria Popp $^{1} \cdot$ Anna-Lena Bettenhausen ${ }^{1}$. \\ Mariam Sobhy Atalla ${ }^{1} \cdot$ Alexander Brack $^{1} \cdot$ Robert Blum $^{2,3} \cdot$ Kathrin Doppler $^{3} \cdot$ Heike Lydia Rittner $^{1}$ (I)
}

Received: 24 November 2020 / Revised: 26 April 2021 / Accepted: 10 May 2021 / Published online: 21 May 2021

(C) The Author(s) 2021

\begin{abstract}
Diabetic polyneuropathy (DPN) is the most common complication in diabetes and can be painful in up to $26 \%$ of all diabetic patients. Peripheral nerves are shielded by the blood-nerve barrier (BNB) consisting of the perineurium and endoneurial vessels. So far, there are conflicting results regarding the role and function of the BNB in the pathophysiology of DPN. In this study, we analyzed the spatiotemporal tight junction protein profile, barrier permeability, and vessel-associated macrophages in Wistar rats with streptozotocin-induced DPN. In these rats, mechanical hypersensitivity developed after 2 weeks and loss of motor function after 8 weeks, while the BNB and the blood-DRG barrier were leakier for small, but not for large molecules after 8 weeks only. The blood-spinal cord barrier remained sealed throughout the observation period. No gross changes in tight junction protein or cytokine expression were observed in all barriers to blood. However, expression of Cldn1 mRNA in perineurium was specifically downregulated in conjunction with weaker vessel-associated macrophage shielding of the BNB. Our results underline the role of specific tight junction proteins and BNB breakdown in DPN maintenance and differentiate DPN from traumatic nerve injury. Targeting claudins and sealing the BNB could stabilize pain and prevent further nerve damage.
\end{abstract}

\section{Key messages}

- In diabetic painful neuropathy in rats:

- Blood nerve barrier and blood DRG barrier are leaky for micromolecules.

- Perineurial Cldnl sealing the blood nerve barrier is specifically downregulated.

- Endoneurial vessel-associated macrophages are also decreased.

- These changes occur after onset of hyperalgesia thereby maintaining rather than inducing pain.

Keywords Neuropathy $\cdot$ Barrier $\cdot$ Pain $\cdot$ Macrophages

Adel Ben-Kraiem and Reine-Solange Sauer contributed equally.

Heike Lydia Rittner

rittner_h@ukw.de

1 Center for Interdisciplinary Pain Medicine, Department of Anesthesiology, University Hospital of Würzburg, 97080 Würzburg, Germany

2 Institute of Clinical Neurobiology, University Hospital of Würzburg, 97078 Würzburg, Germany

3 Department of Neurology, University Hospital of Würzburg, 97080 Würzburg, Germany

\section{Introduction}

Diabetic polyneuropathy (DPN) is the most common diabetes complication. In 10 to $26 \%$ of diabetic patients, DPN is painful [1]. Classical analgesics such as non-steroidal analgesics andwith some exception - opioids are not very effective in neuropathic pain. So, treatment still proves difficult necessitating to identify new targets [2]. Lacking analgesia not only implies patient suffering but also a significant socioeconomic burden [3]. In addition, analgesics only relieve pain and have no beneficial impact on DPN natural history. Other than lifestyle modification and diabetes control, no disease-modifying therapies exist.

DPN starts with an axonopathy due to increased polyol flux, free radical and oxidative stress, mitochondrial 
dysfunction, ischemic or hypoxic microvascular damage, trophic support loss for neurons, and lipid toxicity as well as Schwann cell pathology [4]. In the skin, intraepidermal nerve fibers are lost and nodes of Ranvier become elongated [5], whereas peptidergic fibers increase [6].

The blood-nerve barrier (BNB) consists of the perineurium surrounding nerve fascicles and the endothelium of endoneurial blood vessels [7]. The BNB restricts ions and molecule paracellular flow into the endoneurial milieu. Its perineurial and endoneurial cells are connected by adherens junctions and sealed by tight junctions. In the perineurium, occludin, claudin-1, -3, -19, tricellulin, and TJP1 (ZO-1) are expressed [8-12]. Endoneurial vessels express claudin-5, occludin, and TJP1 [7]. Unlike other neuronal barriers, sealing endoneurial vessels is not only dependent on pericytes but also on vessel-associated macrophages [13]. They recapture molecules leaking through the BNB as there is increased transcytosis in the BNB in comparison to the BBB. Increased barrier permeability like in traumatic nerve injury $[14,15]$ not only facilitates potentially harmful molecule diffusion into the nerve but also supports immune cell transcellular migration by adhesion molecule upregulation [4]. Tight junction protein downregulation, e.g., Cldn1 or Tjp1 [9-12], and junctional adhesion molecules (JAM) or intercellular adhesion molecule upregulation can both contribute to $\mathrm{BNB}$ dysfunction $[4,16]$.

Up to now, it is controversial to which extent BNB, bloodDRG, and blood-spinal cord barriers are affected in preclinical models $[17,18]$ and in patients $[19,20]$ and whether their molecular profile contributes to DPN pathophysiology. We hypothesized that in streptozotocin (STZ)-induced DPN, all barriers are leaky and characteristic tight junction proteins such as Cldn1, Cldn5, and Tjp1 are downregulated.

\section{Research design and methods}

\section{Animal model}

Animal protocols (\# REG 2-264) have been approved by the animal care committee of the provincial government of Würzburg. Male Wistar rats (Janvier labs, Le Genest-St-Isle, France) weighing 180-250 g, free of pathogenic microorganisms, were housed in groups of six in cages, with enrichment tools, in a circadian light rhythm $(12 \mathrm{~h} / 12 \mathrm{~h}$ light/dark cycle, $21-25^{\circ} \mathrm{C}, 45-55 \%$ humidity) with food and water ad libitum. Animals were randomly assigned to groups so that test condition and control animals were in different numbers in each cage. Experiments were conducted during daytime and at indicated time points. Handling procedures were in accordance with international guidelines for the care and use of laboratory animals (EU Directive 2010/63/EU for animal experiments).
Score sheets with defined end points were used daily to monitor animal well-being.

Two experimental groups were compared at different time points: vehicle and STZ (Sigma chemical) injected rats. STZ condition was established by injecting a $45 \mathrm{mg} / \mathrm{kg} \mathrm{STZ}$ in $0.1 \mathrm{M}$ citrate buffer $\mathrm{pH} 4.5$ single intravenous dose [21]. Diabetes induction was verified by blood glucose measurement using Glucosmart $\circledR$. Vehicle rats were injected with $0.1 \mathrm{M}$ citrate buffer $\mathrm{pH} 4.5$.

\section{Behavioral testing}

Mechanical hypersensitivity was determined using the von Frey test $[12,14,22]$. A series of von Frey filaments (Aesthesio® set, UGO BASILE) were assessed to record the hind paw withdrawal threshold and identify mechanical allodynia response and touch sensitivity after STZ injection. In general, the filaments were applied to the hind paw plantar surface and were held for 1-3 s, until the filaments were bent to a $45^{\circ}$ angle. Each paw received stimuli from different filament forces, with a 30-s recovery period between each application. The 50\% von Frey filament paw withdrawal threshold response was determined using Dixon's up and down method [23].

Thermal hypersensitivity was assessed performing Hargreaves test (IITC plantar test apparatus model 400 heated base) [24]. A light source was applied on right hind paw. Measurements were performed two times (with $30 \mathrm{~s}$ intervals). Averages were calculated subsequently.

Motor performance was studied using rotarod. Rats were placed on turning wheels and their performance time (latency to fall from the wheel) was measured $[14,22]$.

\section{Permeability assessment}

To assess capillary permeability to small molecules, rats were intravenously injected with sodium fluorescein (NaFlu, 10\%; $2 \mathrm{ml} / \mathrm{kg}$; MW, $376 \mathrm{Da}$; Sigma-Aldrich). After $30 \mathrm{~min}$, the sciatic nerve, DRG, and spinal cord were harvested followed by $1 \mathrm{~h}$ postfixation in $4 \%$ paraformaldehyde (PFA). In order to study perineurial permeability to small molecules, harvested sciatic nerves were immediately fixed with $4 \%$ PFA for $1 \mathrm{~h}$ and immersed for $15 \mathrm{~min}$ in a $3 \% \mathrm{NaFlu}$ in saline solution and then placed in sucrose $10 \%$ over night prior embedding in Tissue-Tek O.C.T compound [14, 22].

To evaluate the perineurial permeability to macromolecules, harvested sciatic nerves were immediately fixed with 4\% PFA for $1 \mathrm{~h}$ and immersed in $2 \mathrm{ml}$ of Evans blue albumin (EBA, 5\% bovine albumin labeled with $1 \%$ Evans blue; both from Sigma Chemicals, $68 \mathrm{kDa}$ ) for $1 \mathrm{~h}$ [22]. Afterwards, tissues were embedded in Tissue-Tek O.C.T compound (ref. 4583 ) and cut. Sections of $10 \mu \mathrm{m}$ obtained were analyzed by microscopy (Keyence BZ-9000). 
Endothelial permeability to larger macromolecules was also assessed in sciatic nerves and DRG with immunofluorescence directed against fibrinogen $(340 \mathrm{kDa})$. Frozen sciatic nerves and DRG tissue were cut in sections and fixed with ice cold acetone. Sections were permeabilized with $0.5 \%$ Triton-X100 in phosphate-buffered saline and blocked in 1\% goat serum in phosphate-buffered saline and $3 \%$ bovine serum albumin in phosphate-buffered saline. Then, they were incubated with primary antibody goat anti fibrinogen (1:100 RRID: AB_10787808) and secondary antibody donkey anti goat Alexa fluor 594 (1:600 RRID: AB_2762828). Stained sections were analyzed by microscopy (Keyence BZ-9000).

\section{Laser microdissection}

Sciatic nerves and DRG from male Wistar rats embedded in Tissue-Tek O.C.T compound (ref. 4583) and stored at $-80^{\circ} \mathrm{C}$ were sectioned using Leica CM3050S cryostat. Sections of $20 \mu \mathrm{m}$ were collected on Arcturus ${ }^{\circledR}$ PEN membrane glass slides (applied biosystems ref: LCM0522) treated with RNAse Away spray (Sigma-Aldrich ref: 83931). Sections went through toluidine blue staining before laser microdissectin (LMD). Once the sections were stained, slides were set in Leica LMD6 microscope coupled with a $355 \mathrm{~nm}$ laser. Using the Leica LMD V7.6 software, different tissue areas were selected and dissected. In the sciatic nerve, capillaries and perineurium were dissected. In DRGs, capillaries and the fiber-rich region were dissected. Furthermore, the entire neuron-rich region and the perineurium-like area were dissected. Samples were collected in 0.2-ml PCR soft tubes (Biozym 711080) and stored at $-80^{\circ} \mathrm{C}$.

\section{Reverse transcription quantitative PCR}

Entire sciatic nerve, DRG, and spinal cord were harvested and dissected. Total RNA was extracted with Trizol (Invitrogen) or the miRNeasy kit. Next, $1 \mu \mathrm{g}$ was transcribed to cDNA using the high capacity cDNA-kit (Applied Biosystems, Life technologies) following manufacturer's instructions. Gapdh was used as a reference gene for quantification. RTqPCR analysis was performed using the following primers (MWG Eurofins, Ebersberg, Germany) with the SYBRGreen method:

Cldn1 (fw GGGACAACATCGTGACTGCT and rev CCACTAATGTCGCCAGACCTG), Cldn 5 (fw AAATTCTGGGTCTGGTGCTG and rev GCCGGTCA AGGTAACAAAGA), Cldn12 (fw AACTGGCCAAGTGT CTGGTC and rev AGACCCCCTGAGCTAGCAAT), Cldn 19 (fw TGCTGAAGGACCCATCTG and rev TGTGCTTGCTGTGAGAACTG), Jam3 (fw TGCTGCTC TTCAGGGGCTGCGTGAT and rev AACACATC TGTGCGACCGGCCAGGT), Ocln (fw TGGGCAGT CGGGTTGACT and rev GGGCATCATGGTGTTCATTG ), Tric (fw TGAATGGCCACCAGTGACCGA and rev
AGTCAGGCATTACGATGGGCTTAG), Tjp 1 (fw CACGATGCTCAGAGACGAAGG and rev TTCTACAT ATGGaAgtTGgGGATC), Tnfa (fw ACCACGCT CTTCTGTCTACTG and rev CTTGGTGGTTTGCT ACGAC), $I l 10$ (fw AGACCCACATGCTCCGAGAG and rev GGGCATCACTTCTACCAGGT), Il6 (fw CTGCTCTG GTCTTCTGGAGT and rev TGGAAGTTGGGGTA GGAAGG), and Gapdh (fw AGTCTACTGGCGTCTTCAC and rev TCATATTTCTCGTGGTTCAC). RTqPCR analysis was carried out by a 7300 Real-Time PCR System (Applied Biosystems, Thermo Fischer) with the following program: 50 ${ }^{\circ} \mathrm{C}$ for $2 \mathrm{~min}, 95^{\circ} \mathrm{C}$ for $2 \mathrm{~min}$, and 40 cycles at $95^{\circ} \mathrm{C}$ for $3 \mathrm{~s}$ and $60{ }^{\circ} \mathrm{C}$ for $30 \mathrm{~s}$. Samples were analyzed as triplicates. Relative mRNA abundances to Gapdh were calculated by the $\Delta \Delta \mathrm{Ct}$ method (threshold cycle value). To compare different samples, the control condition (vehicle animals) was set at 1 .

Following LMD, total RNA was extracted using RNeasy® Micro Kit (Quiagen cat. no. 74004) Total RNA (1 $\mu \mathrm{g})$ was transcribed to cDNA using the high-capacity cDNA kit (Applied Biosystems Life technologies) following the manufacturer's instructions. QPCR analysis was performed with the following primers using the Taqman method: Cldn1 (Thermo Fisher cat\# Rn00581740_m1), Cldn5 (Thermo Fisher cat\# Rn01753146_s1), von Willebrand Factor (Vwf; Thermo Fisher cat\# Rn01492158_m1), Tjp1 (Thermo Fisher cat\# Rn02116071_s1), and Gapdh (Thermo Fisher cat\# Rn01462662_g1). QPCR analysis was carried out using the StepOnePlus Real-Time PCR System (Applied Biosystems) with the following program: fast $40 \mathrm{~min}$ for a run, $95^{\circ} \mathrm{C}$ for 20 $\mathrm{s}$, and 45 cycles at $95^{\circ} \mathrm{C}$ for $1 \mathrm{~s}$ and $60^{\circ} \mathrm{C}$ for $20 \mathrm{~s}$. Samples were analyzed as triplicates. Target cDNAs were normalized to endogenous control (Gapdh).

\section{Immunofluorescence and fluorescence microscopy}

Frozen sciatic nerves and DRG tissues were sectioned and fixed with ice-cold acetone. Sections were permeabilized with $0.5 \%$ Triton-X100 in phosphate-buffered saline (PBS) and blocked in $1 \%$ goat serum in PBS and 3\% bovine serum albumin in PBS. Then, they were incubated with primary antibodies mouse anti human, rat, canine claudin-1 (1:100; RRID AB_2533323), mouse anti human, rat-claudin-5 (1:100; RRID AB_2533200), rabbit anti-von Willebrand factor (vWF) (1:100; RRID:AB_2315602), mouse anti rat CD68 (RRID:AB_2291300), mouse anti rat RECA-1 (1:100; RRID:AB_935279), and rabbit anti rat CD206 (1:100; RRID:AB_1523910) overnight, following sequential incubation with secondary antibodies: donkey anti-mouse Alexa Fluor 555 (1:600; RRID:AB 2536180), goat anti-mouse FITC (1:600; RRID:AB 259378), donkey anti-rabbit Alexa Fluor 555 (1:600; RRID:AB 162543), and donkey anti-rabbit Alexa Fluor 488 (1:600, RRID:AB_2535792). DAPI 2 mg/ml in distilled water (Ref D9542, Sigma Aldrich) was used to 
stain nuclei. ProTag Mount-Fluor was employed for mounting the sections (Biocyc, Luckenwalde, Germany), and fluorescence microscopy was performed (Olympus BX51, camera Olympus DpP71).

\section{Western blot}

Eight weeks after injection of either vehicle solution or STZ sciatic nerves were harvested and homogenized in RIPA lysis buffer (50 mM Tris pH 8.0; $150 \mathrm{mM} \mathrm{NaCl} ; 0.1 \%$ SDS; 0.5\% Na-deoxycholate; $1 \%$ NP40) with proteinase inhibitor (Complete, Roche Applied Science) and placed in tissue lyser for $5 \mathrm{~min}$ at maximal frequency of 30 . Homogenates were then centrifuged at $450 \mathrm{~g}$ for $10 \mathrm{~min}$ at $4{ }^{\circ} \mathrm{C}$. Supernatants were then centrifuged for $60 \mathrm{~min}$ at $20,000 \mathrm{~g}$ at $4{ }^{\circ} \mathrm{C}$ to precipitate the membrane fraction. The cytosolic fraction in the supernatant was transferred to another tube and the precipitated membrane fraction dissolved in RIPA lysis buffer with proteinase inhibitors. Proteins were quantified with BCA protein assay reagent (Pierce, Rockford, IL, USA). Aliquots of protein were mixed with sodium dodecyl sulfate (SDS) containing buffer (Laemmli), denatured at $60^{\circ} \mathrm{C}$ for $5 \mathrm{~min}$, fractionated on SDS polyacrylamide gels, and subsequently blotted onto nitrocellulose membranes (Amersham ${ }^{\mathrm{TM}}$ catalogue number: 10500001). Proteins were detected using specific antibodies: mouse anti claudin-5 1:200; RRID AB_2533200, mouse IgG HRP conjugated 1:3000 RRID: AB_330924 and-as protein loading control $-\beta$-actin HRP conjugated, 1:20,000 RRID: AB_262011. For quantification, claudin-5 band intensities were normalized to their $\beta$-actin loading control band.

\section{Image analysis}

Bioimages were analyzed using FIJI (ImageJ) software. For each image, regions of interest (ROI) were segmented manually and the fluorescence intensity (mean gray value) was measured in corresponding ROIs. Then, we subtracted the background to the measured intensities; the results obtained correspond to the actual signal intensity. Per animal, five to six images were analyzed, from which an individual mean fluorescence intensity was calculated per animal. To quantify claudin-5 specifically in capillaries, sections were co-stained for von Willebrand factor (vWF). After quantifying both claudin-5 and vWF following the above described method and assuring that there were no changes in $\mathrm{vWF}$ expression, we normalized claudin-5 fluorescence intensity on vWF fluorescence intensity. In order to quantify vessel-associated macrophages, sections were co-stained either for CD68 and vWF or CD206 and RECA-1. The total number of macrophages (CD68+ or CD206+) near blood vessels (vWF+ or RECA$1+)$ was counted and expressed relative to the total number of capillaries in the endoneurium.

\section{Statistical analysis}

Data are presented as mean \pm SEM and medians and interquartile range. Two groups were compared by $t$ test for independent variables or Mann-Whitney non-parametric test. Multiple measurements with one or two variables (e.g., time and treatment) were analyzed by one- or two-way ANOVA or by repeated measurements (RM), two-way ANOVA, and Friedman's nonparametric test, as appropriate and described in the figure legends. Differences were considered significant if $p<0.05$.

\section{Results}

Mechanical hypersensitivity and motor impairment in diabetic Wistar rats To validate the model, we measured blood glucose and observed a four-times increased level for all STZinjected rats 1 week after injection and a seven-times higher level 4 to 8 weeks after injection (Fig. 1a, b). We confirmed mechanical hypersensitivity starting at 2 weeks after STZ by von Frey hair test (Fig. 1c) but did not detect thermal hypersensitivity in the Hargreaves test (Suppl. Fig. 1) in line with the previous findings [25]. Performance time on the rotarod, a measure of motor function, was impaired in STZ-treated rats (Fig. 1d).

Increased capillary permeability to small molecules, but normal tight junction protein expression in DRG After NaFlu (376 Da) injection, fluorescence increased in diabetic rat neuron-rich region and fiber-rich region of DRG at 8 weeks indicating increased capillary permeability for small molecules (Fig. 2a-c). At 8 weeks, we could not observe that fibrinogen - a blood-borne large molecule $(340 \mathrm{kDa})$ - increased immunoreactivity (Fig. 2d, e).

Cldn1 and Cldn5 seal endothelia, Cldn12 and Cldn19 protect the perineurial and myelin barrier, Tric and - in partOcln are important in shielding tricellular junctions. Jam3 allows for cellular adhesion and Tjp1 anchors tight junction proteins with the intracellular cytoskeleton (Fig. 3a) [7]. In whole DRGs, unaltered RNA expression level of these tight junction proteins was observed at 4 and 8 weeks (Fig. 3b, c). We then hypothesized that changes could be more selective in particular DRG areas. Therefore, we used LMD in order to separately analyze expression levels of corresponding barrier proteins in the DRG neuron-rich and fiber-rich region [15]. However, Cldn1 and Tjp1 expression levels in the neuron-rich region and $C l d n 5$ in capillaries were unchanged 8 weeks after STZ (Fig. 3d). Likewise, claudin-1 and claudin-5 immunoreactivity in vWF-positive vessels and vWF-associated CD68+ macrophages were unaffected (Fig. 3e-j and Suppl. Fig. 2a for full size insert of CD68/vWF). In summary, 8 weeks after STZ-DPN induction, the DRG is more permeable for small 
Fig. 1 Mechanical hypersensitivity and impairment of motor performance in STZinduced diabetes type I in rats. a Male Wistar rats were treated with i.v. streptozotocin (STZ; once 45 $\mathrm{mg} / \mathrm{kg}$ ): experimental outline for tests and tissue harvest (created with biorender.com). b Blood glucose in $\mathrm{mg} / \mathrm{dl}$, c mechanical allodynia measured by von Frey hairs (g), and $\mathbf{d}$ motor function by rotarod (s). All data points represent mean \pm SEM. $* P<0.05$ $(n=6)$. Two-way repeated measurement ANOVA and Bonferroni post hoc test for multiple comparisons. For rotarod, $\mathbf{d}$ data points represent median and interquartile range. $* * * P<0.001$ $(n=6)$; Friedman test and Dunn's post hoc tests for multiple comparison b
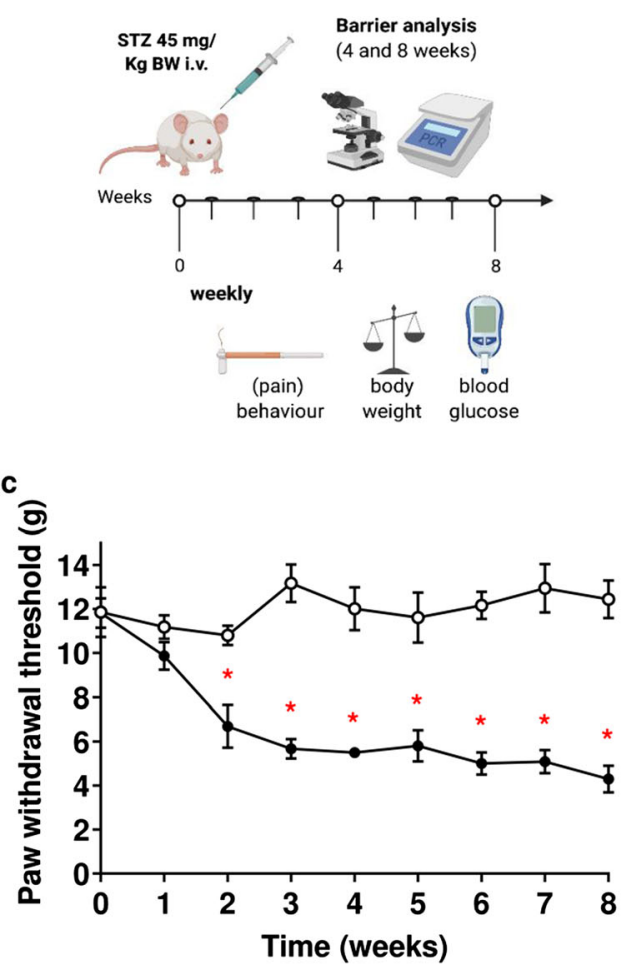

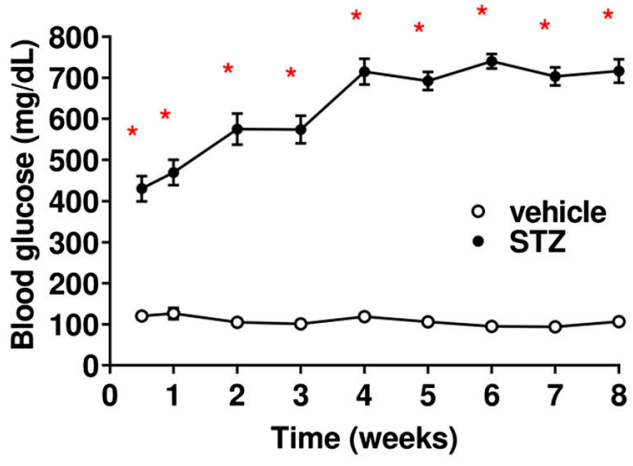

d

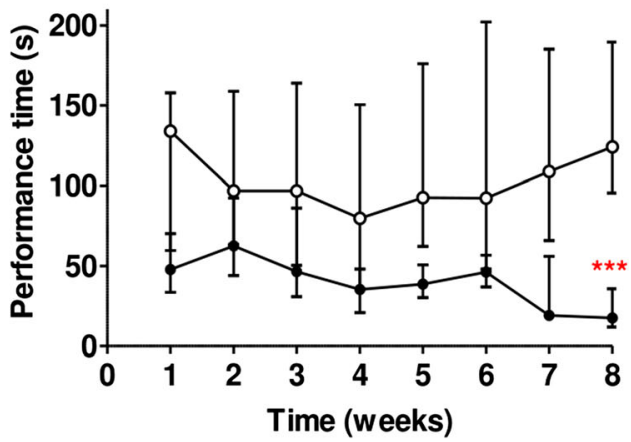

molecules, but not for macromolecules, and this effect is independent of tight junction protein expression level.

After traumatic nerve injury, the blood-spinal cord barrier is leakier and Cldn5 and Tjpl are downregulated [14]. In DPN, endothelial permeability to small molecules as well as tight junction protein expression were unchanged in STZtreated animals (Suppl. Fig. 3). Thus, the blood-spinal cord barrier is intact.

\section{Capillary, perineurial leakiness, and perineurial claudin-1 loss}

in STZ-induced DPN Fluorescence in sciatic nerve endoneurium was enhanced after in vivo (capillary barrier, Fig. $4 \mathrm{a}-\mathrm{c}$ ) and ex vivo (perineurial barrier, Fig. 4d, e) NaFlu application in STZ rats at 8 weeks - indicating capillary and perineurial barrier leakiness. No permeability changes were observed when nerves were stained for fibrinogen $(340 \mathrm{kDa}$, capillary barrier) (Fig. 5a, b). Likewise, sciatic nerve incubation with EBA (68 kDa) demonstrated no endoneurial diffusion (perineurial barrier, Fig. 5c, d)

In addition, in whole nerve-isolated RNA samples, the expression of a panel of tight junction proteins was unaltered (Fig. 6a, b). When mRNA expression was analyzed in perineurium-microdissected tissue samples and from the capillaries, a perineurial Cldn 1 and an endoneurial Cldn5 downregulation (Fig. 6c, d) were seen.

To visualize the corresponding proteins, claudin-1 and -5 immunoreactivity was quantified in these areas. This showed reduced perineurial claudin-1 immunoreactivity at 8-week STZ-induced DPN (Fig. 7a, b). Endoneurial claudin-5 immunoreactivity in the vWF-positive capillaries was similar in both groups (Fig. 7c, d) and this is confirmed by claudin-5 Western blot showing no difference between groups (Fig. 7e).

No signs of inflammation in STZ-induced diabetic neuropathy, but decreased vessel-associated-macrophage number Cytokines like TNF $\alpha$ are known to regulate tight junction protein expression [26]. We therefore selected interleukin-6 and $\mathrm{TNF} \alpha$ as pro-inflammatory cytokines and interleukin-10 as an anti-inflammatory cytokine (Suppl. Fig. 4). Il6, Il10, and Tnfa expression was unaffected in the sciatic nerve, both, at 4 and 8 weeks after STZ injection. Likewise, there was no increased CD68+ macrophage infiltration observable in the sciatic nerve.

The barrier composition of specifically endoneurial capillaries is different from the blood-brain barrier, because not only pericytes but also macrophages (vessel-associated macrophages) prevent large molecule penetration [13].

In the sciatic nerve of STZ-treated rats, significantly less CD68+ macrophages were associated to vWF+ capillaries in comparison to vehicle control (Fig. 7f, g and Suppl. Fig. $2 \mathrm{~b}$ for full size insert). Vessel-associated macrophages could be further classified as CD206+ anti-inflammatory M2 macrophages [27] adjacent to RECA-1 positive endoneurial capillaries [28]. The number of CD206+ vessel-associated 


\section{a Dorsal root ganglion}
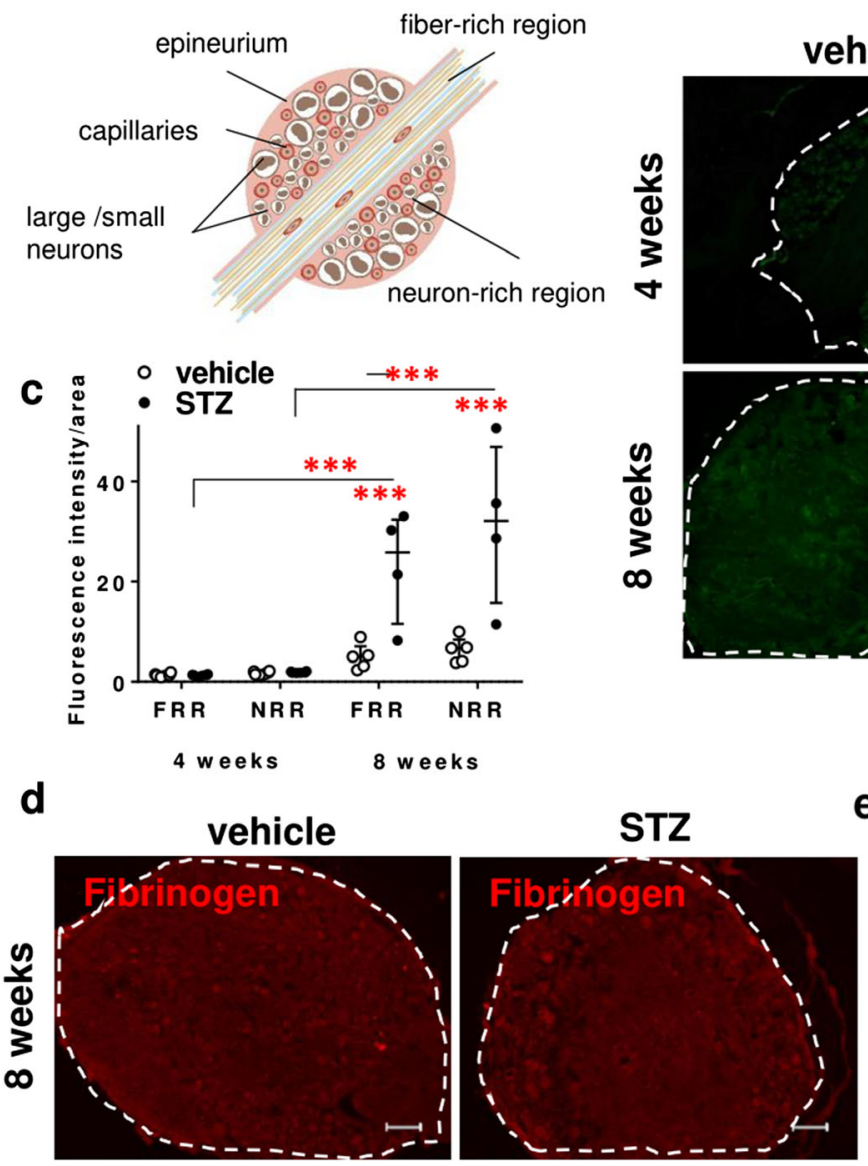

Capillary barrier
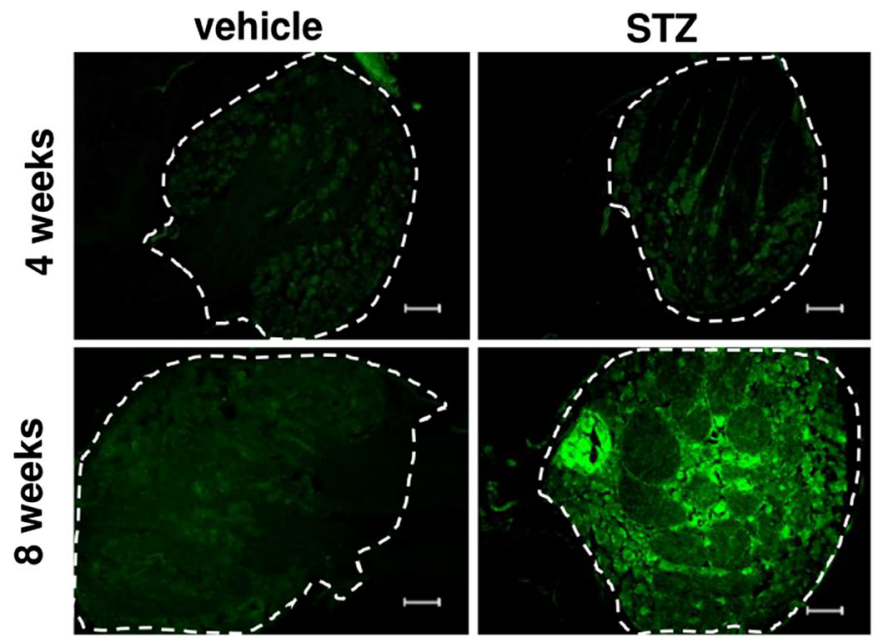

Fig. 2 Increased selective capillary permeability to small molecules in dorsal root ganglia. a Diagram of the DRG with neuron-rich region (NRR) and fiber-rich region (FRR). b, $\mathbf{c}$ Male Wistar rats were i.v. injected with sodium fluorescein $30 \mathrm{~min}$ before sacrifice. Fluorescence

macrophages was reduced 8 weeks after STZ injection (Fig. $7 \mathrm{~h}$, i and Suppl. Fig. 2c for full size insert). Thus, less vesselassociated macrophages and not lower tight junction protein expression are observed at the time point of capillary leakiness in STZ-induced diabetes.

\section{Discussion}

In the present study, we provide evidence for small molecules BNB leakiness in STZ-induced DPN: decreased perineurial claudin-1 expression explains a higher perineurial permeability, while a decreased vessel-associated M2 macrophages could be responsible for enhanced endothelial diffusion. The blood-DRG barrier, but not the blood-spinal cord barrier, was also leakier for small molecules. BNB, blood-DRG, and blood-spinal cord barrier remained sealed for larger molecules. No signs of neuroinflammation, e.g., increased macrophage infiltration or proinflammatory cytokines, were detected. Moreover, all observed barrier changes occurred between was quantified in the neuron-rich region and fiber-rich region of the DRG, $n=4-5$. Two-way ANOVA and Bonferroni post hoc test for multiple comparisons; $* * * P<0.001$. d, e Fibrinogen immunostaining and respective quantification in the dorsal root ganglion, $n=6$

4 and 8 weeks - long after the first detection of mechanical hypersensitivity. Consequently, a destabilized BNB could be responsible for maintaining - rather than initiatingneuropathic pain as well as further nerve damage.

Previous studies have documented increased peripheral nerve permeability for small but not macromolecules in STZ-induced diabetes after 9 months [17]. Additionally, endoneurial edema is an early sign of STZ-induced diabetes

Fig. 3 Unchanged tight junction protein expression in dorsal root ganglia in diabetic rats. MRNA was extracted from entire DRG of male Wistar rats treated with STZ i.v. or vehicle. a Schematic of the tight junction and its proteins (created with biorender.com). b, c Relative tight junction protein mRNA expression in DRG: Cldn1, Cldn5, Cldn12, Cldn19, Jam3, Ocln, Tric, and Tjp1 (ZO-1) in entire DRG. d Relative mRNA expression of Cldn1, Tjp1 in the neuron-rich region and Cldn5 in capillaries separated with laser microdissection $(n=6)$, Mann-Whitney for comparison. e-h Staining for claudin-1 or claudin-5 and von Willebrand factor and quantification in selected areas $(n=5-6)$. $\mathbf{i}, \mathbf{j}$ Staining for CD68 and von Willebrand factor and quantification $(n=5-$ 6), arrows depict examples. Scale bars $=100 \mu \mathrm{m}$ and $20 \mu \mathrm{m}$ in the insert, dot plots represent median and interquartile range, Mann-Whitney test 
a

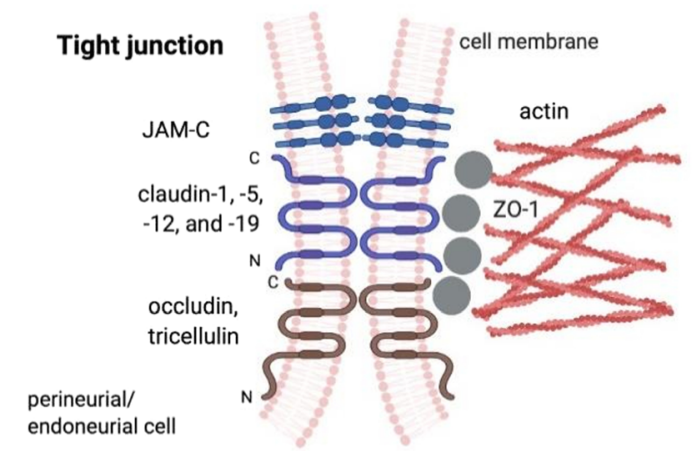

b

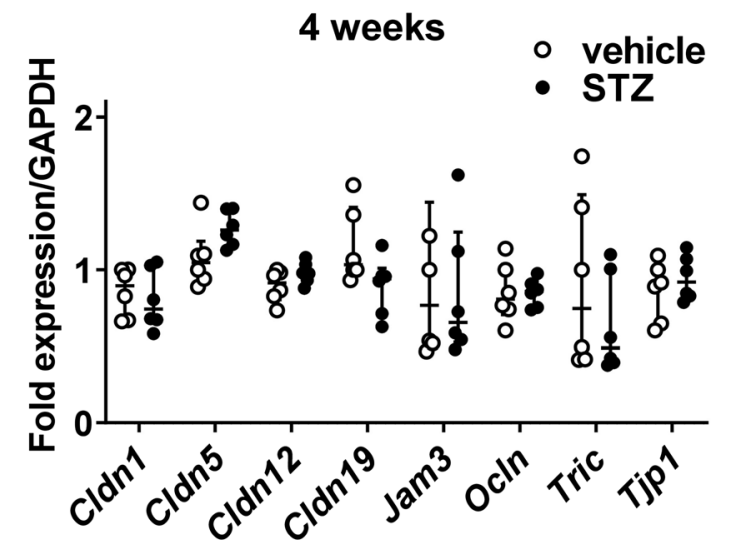

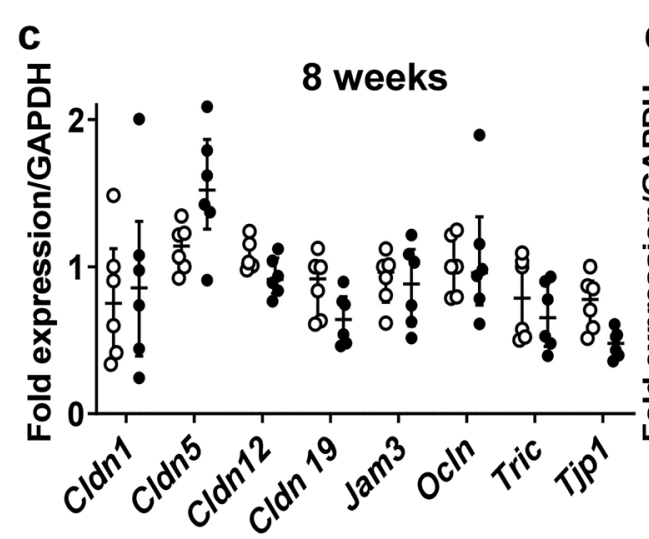

e

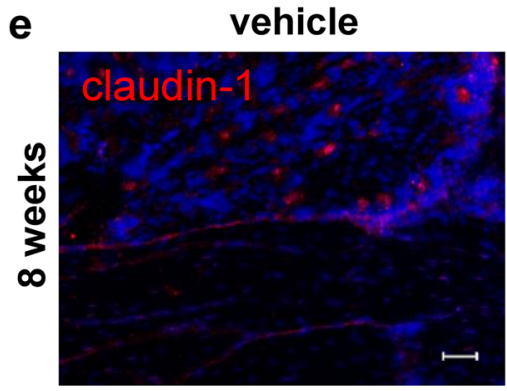

g

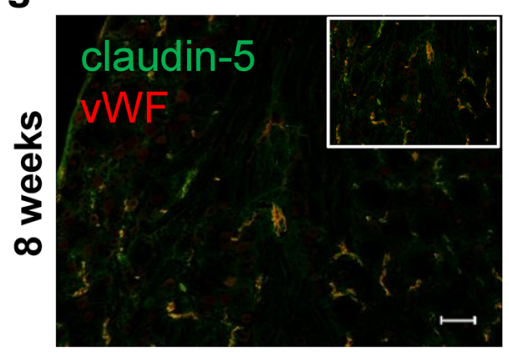

i

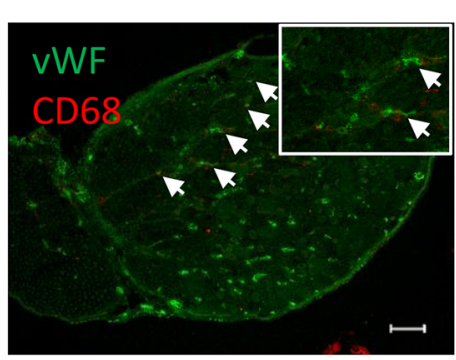

d
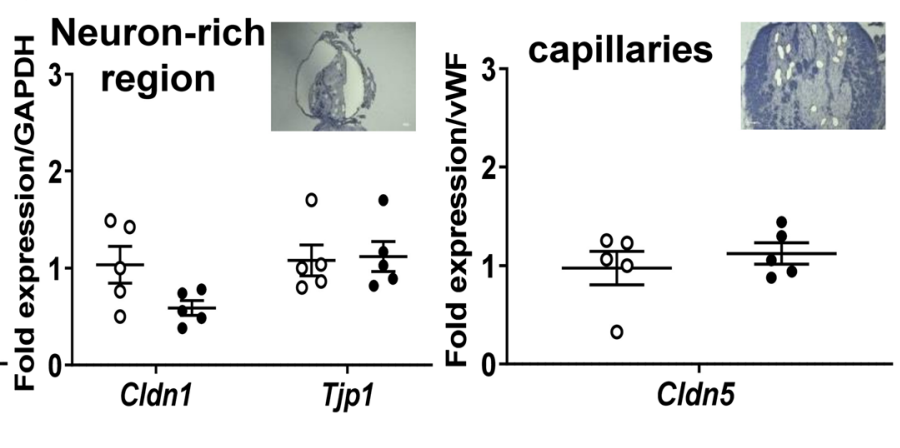
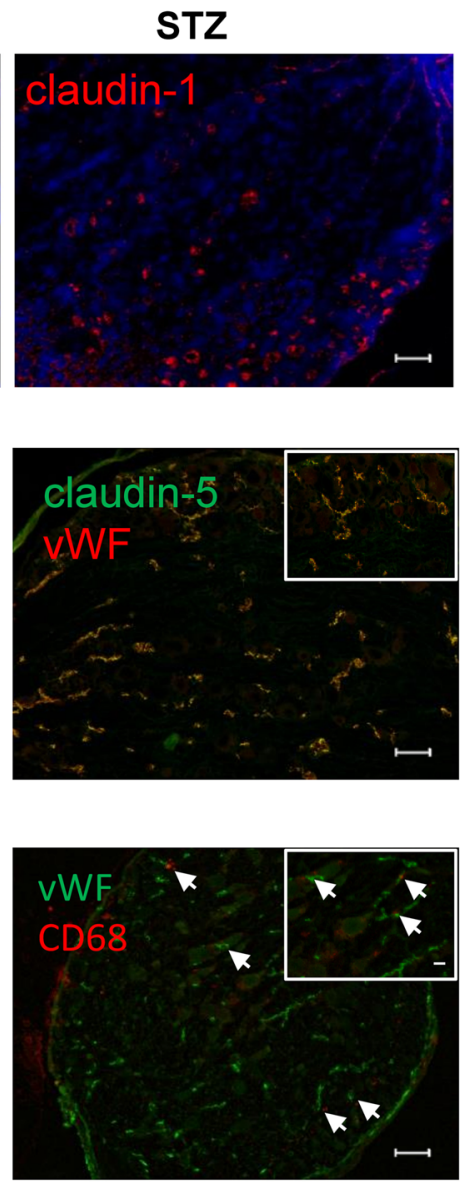

f

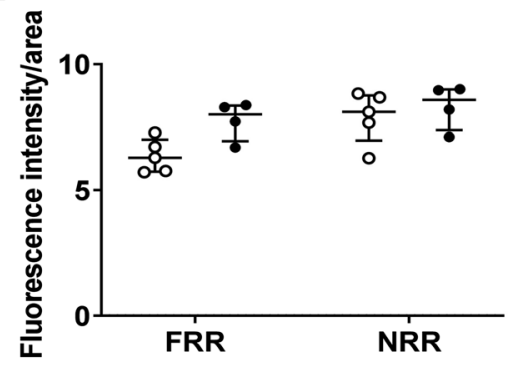

h

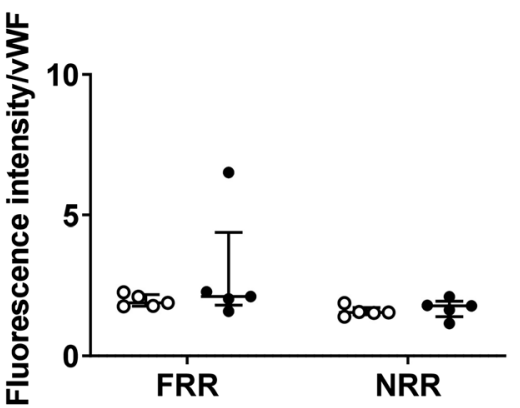

j

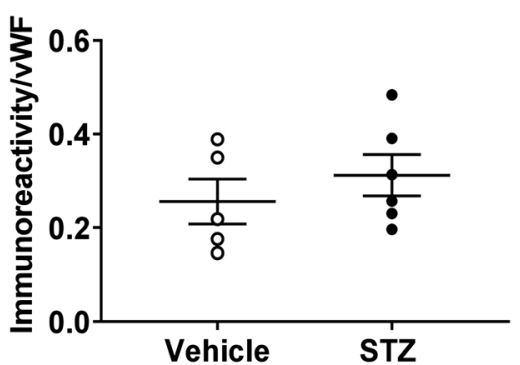


[29], but not in all studies and models [30]. Therefore, our results are in accordance with previous smaller studies. Increased perineurial permeability can be explained by a local loss of $C \ln d 1$ - a major sealing tight junction protein of the perineurium. Macromolecular leakiness has been observed in type 1 diabetes rat models [31] and type 2 diabetes [18], but not other studies [4]. Longer disease duration in type 2 diabetes could result in increased leakiness to larger molecules.

Microvascular changes in DPN include degradation of paracellular tight junction, loss of pericytes, increased basement membrane thickness, and fibrin positive blood vessels as well as endothelial cell hyperplasia [4]. The vascular tight junction protein $\mathrm{Cldn} 5$ is an essential protein in the blood-brain barrier [32]. Cldn 5 mRNA, but not claudin-5 protein, was decreased in the endoneurium in STZ-induced DPN. It is possible that reduced Cldn 5 mRNA results in decreased claudin-5 protein at later time points. But, the decreased number of bloodvessel-associated macrophages in endoneurium could explain the increased small molecule endothelial permeability [13] in synergy with pericyte activity and loss $[4,16]$.

In the DRG in STZ-induced DPN, a leakiness to small molecules was observed but unchanged tight junction
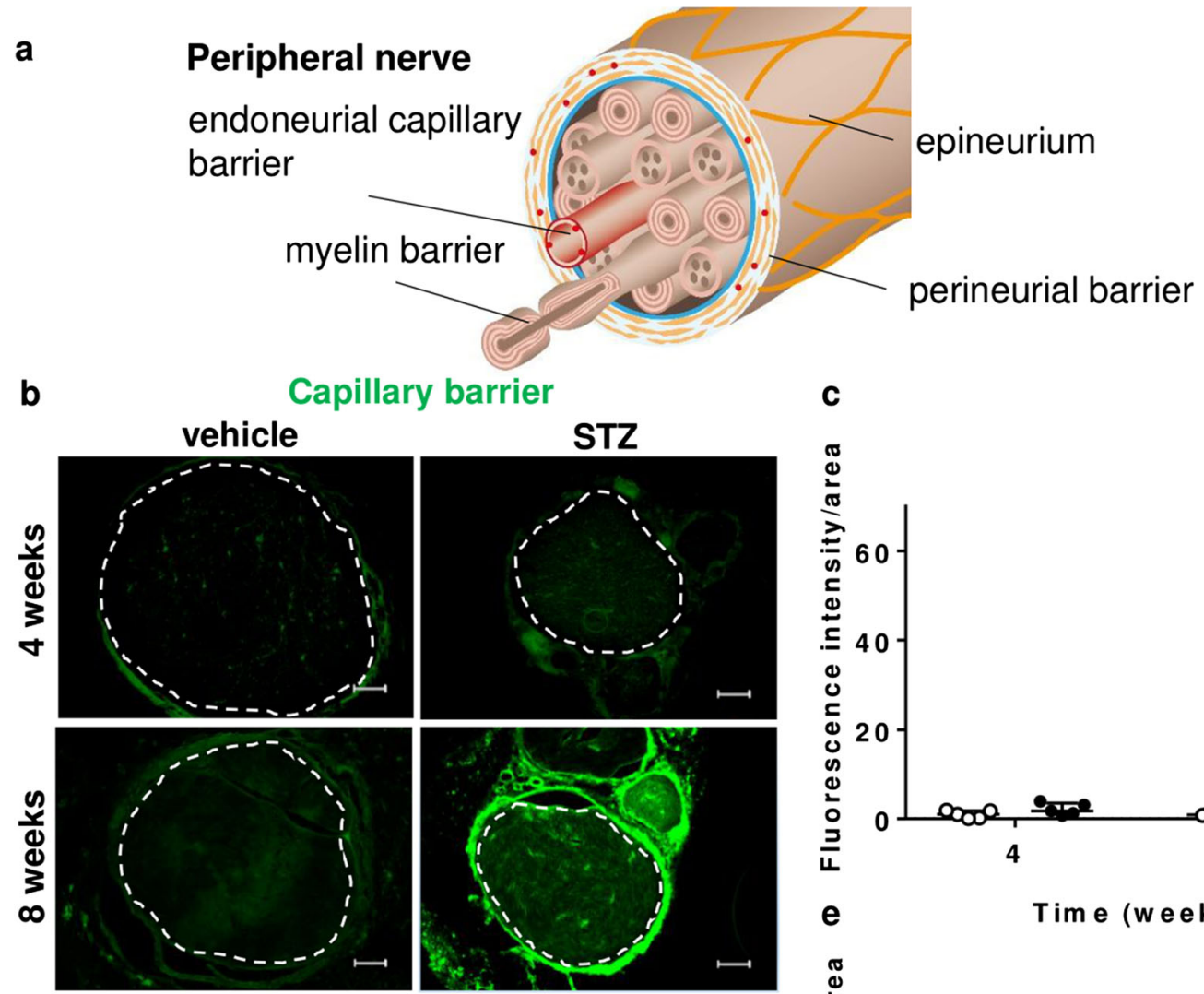

C
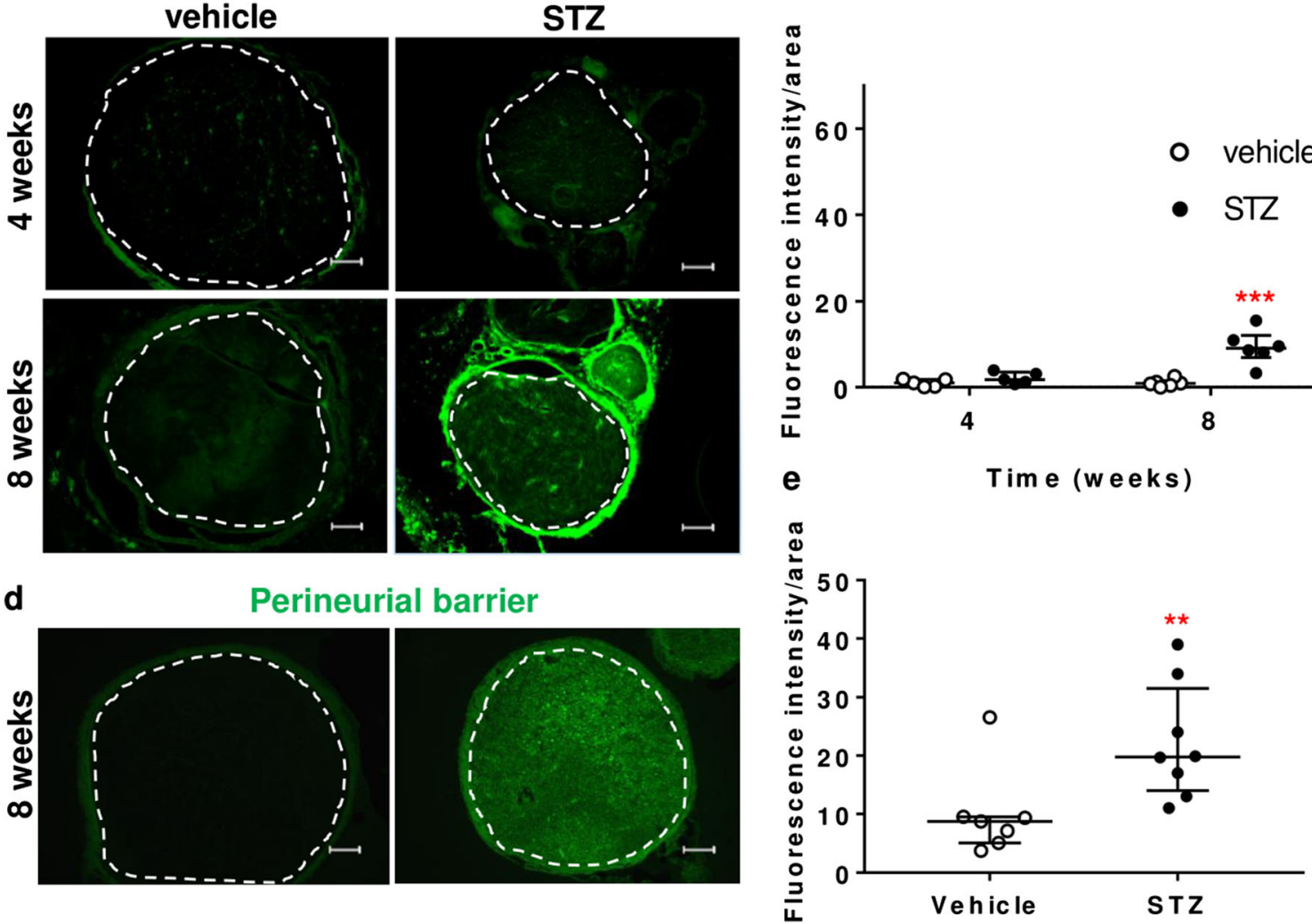

Fig. 4 Increased capillary and perineurial permeability for small molecules in prolonged STZ-induced DPN. a Barriers in the peripheral nerve. $\mathbf{b}, \mathbf{c}$ Diabetic and non-diabetic male Wistar rats were treated with i.v. sodium fluorescein ( $376 \mathrm{Da}) 30 \mathrm{~min}$ before sacrifice to measure the tightness of the capillary barrier, $n=5-6$. d, e Sciatic nerves were collected and immersed in $3 \%$ sodium fluorescein to analyze the perineurial barrier tightness, $n=7-8$. Quantification of fluorescence intensity normalized by the stained area (dashed line) is depicted in $\mathbf{c}$ and $\mathbf{e}$. Scale bars $=100 \mu \mathrm{m}$, dot plots represent median and interquartile range (c). two-way ANOVA, $* * * P<0.001(\mathbf{e})$. Mann-Whitney test, $* * P<0.01$ 


\section{Capillary barrier}

a

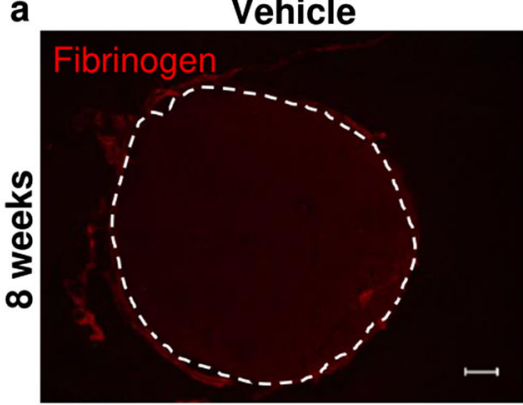

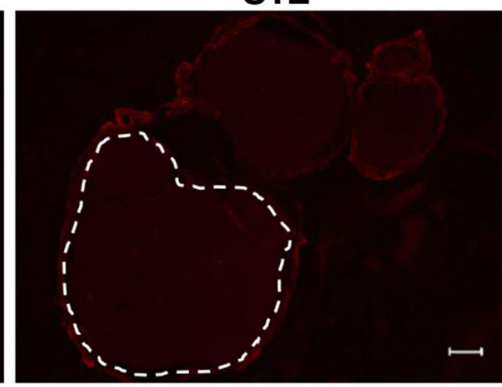

C
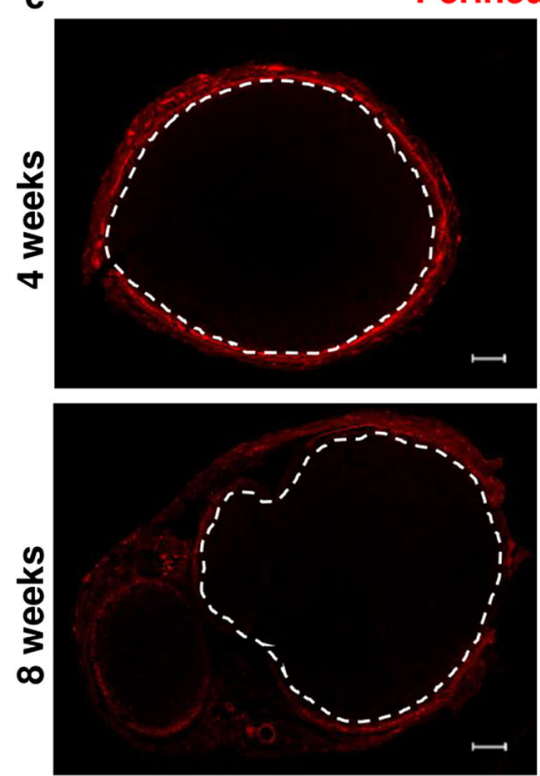

Fig. 5 Preserved blood-nerve barrier function for macromolecules in the sciatic nerve. Sciatic nerve from male Wistar rats was harvested and a, b stained against fibrinogen $(340 \mathrm{kDa})$ or c, d incubated in Evans blue albumin $(68 \mathrm{kDa})$ for $1 \mathrm{~h}$. a Endoneurial immunoreactivity against
STZ

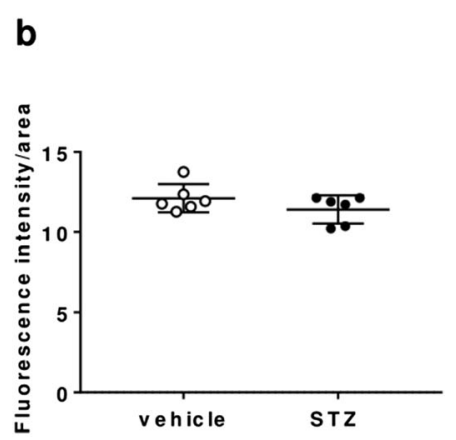

d
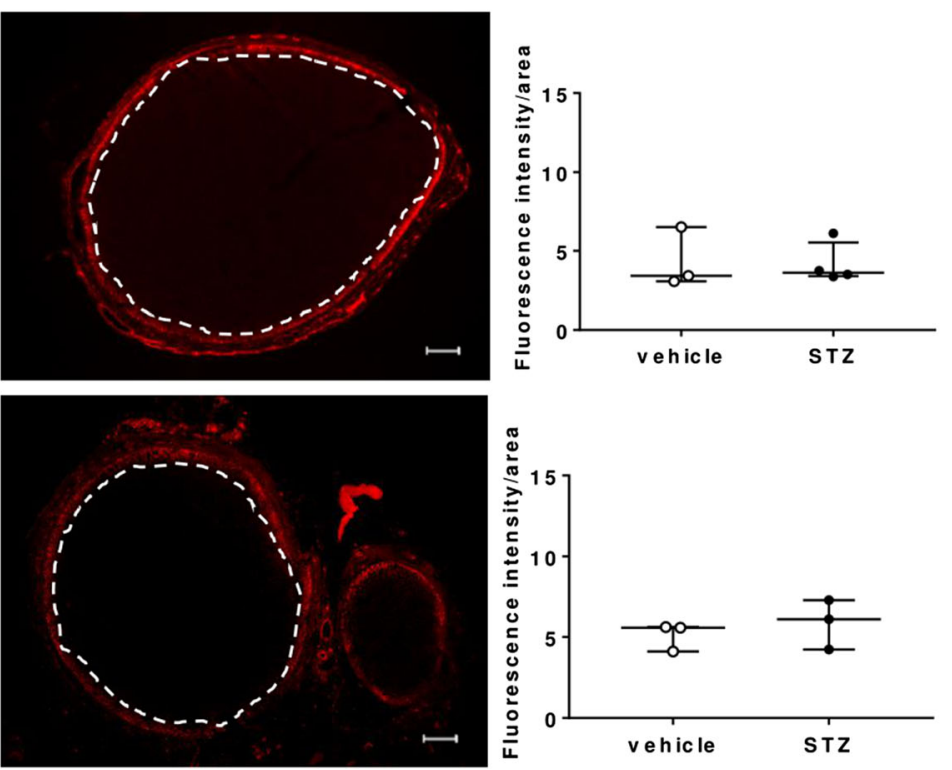

fibrinogen 8 weeks after STZ or vehicle, $n=6$. $\mathbf{c}$ Penetration of Evans blue albumin into the endoneurium 4 and 8 weeks after STZ, $n=3$. Fluorescence intensity was quantified and normalized to the region of interest (dashed line). Scale bars $=100 \mu \mathrm{m}$

proteins. Increased leakiness could be due to, e.g., increased transcytosis or changes in gap junction proteins [33]. Since our experimental design covered only 8 weeks, tight junction proteins could be affected at later time points.

No changes were seen in the blood-spinal cord barrier permeability in our study. We did not examine the blood-brain barrier, but changes in diabetes have been reported: $\mathrm{Cldn} 5$ and pericyte coverage are decreased in old diabetic mice [34] and claudin-5 forms larger gaps in brain capillaries after 8 weeks STZ-induced diabetes together with cognitive impairment [35] So, several barriers are affected in diabetes, but the role of specific tight junction proteins like claudin-5 seems to depend on anatomical location as well as duration and type of diabetes.

Blood-DRG and blood-spinal cord barrier permeability alterations seem to crucially depend on the type of neuropathy: the blood-spinal cord barrier is leaky after nerve injury [14] and chemotherapy-induced neuropathy [36] but unchanged in
DPN - as shown here. Blood-DRG barrier permeability is increased in DPN, but not after traumatic nerve injury [15].

At the moment, it is unclear whether other barriers in the nerve itself might be affected in DPN. Claudin-19 is the major myelin barrier sealing protein. Recent studies support a role of Schwann cells in diabetes [37]. In fact, the myelin sheath lipid composition is altered in STZ-induced DPN [38]. Therefore, studying the myelin barrier in more detail might unravel new pathologies in DPN.

Mechanical allodynia occurred already 2 weeks after STZ injection prior to the increase in permeability. This suggests that at least during the early stages of diabetes, allodynia is caused by other (axonal) factors. Short-term opening of the BNB using claudin-1 interference peptides, tissue plasminogen activator via the low-density receptor protein-1 pathway or hypertonic saline leave nociceptive thresholds unaltered $[12,22,24]$. Indeed, in addition to a leaky barrier, an "insult" like systemic proinflammatory cytokine profile or other 
Fig. 6 Decreased Cldn1 and Cldn 5 mRNA in perineurium and capillaries, respectively. a-d MRNA expression of tight junction proteins of male Wistar rats treated or not with STZ i.v. injection $\mathbf{a}, \mathbf{b}$ either form the whole sciatic nerve $(n=6)$ or $\mathbf{c}, \mathbf{d}$ after tissue dissection with laserassisted microdissection - as depicted in the inserts. MRNA expression of claudin $1,5,12$, and 19 (Cldn1, Cldn5, Cldn12, Cldn19), junctional adhesion molecule C (JAM-C, Jam3), occludin (Ocln), tricellulin (Tric), and zona occludens-1 (ZO-1, Tjp1) was calculated relative to GAPDH. Dot plots represent medians and interquartile range. All $n=5-6, * * P<0.01$ and $* P<$ 0.05 . Mann-Whitney test $(\mathbf{a}-\mathbf{c})$ and unpaired $t$ test (d)

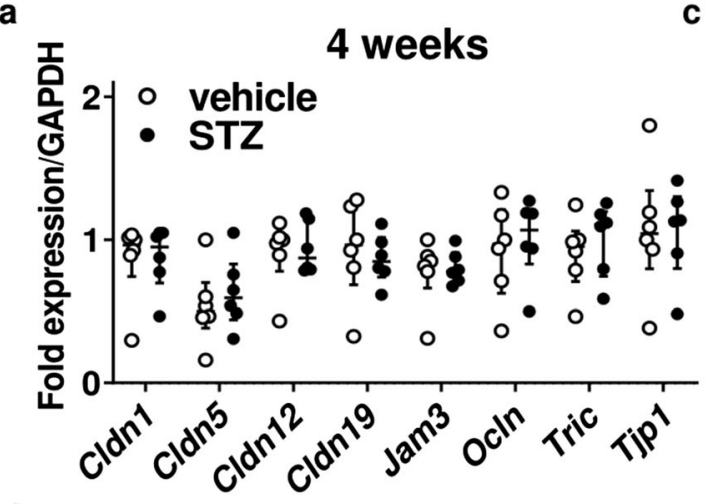

b

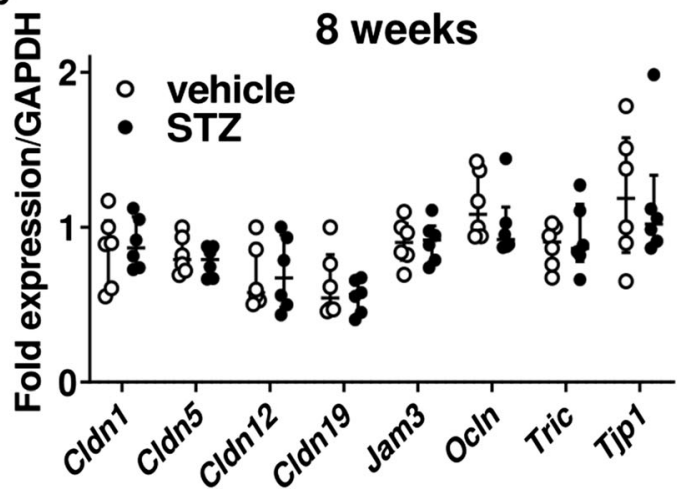

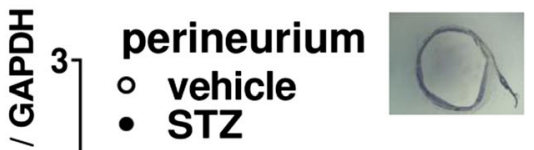

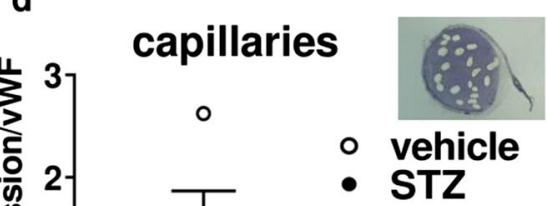

proalgesic mediators like methylglyoxal is needed in DPN [39-41]. This is also observed when the inflammatory milieu in traumatic nerve injury affects barrier functions [9-12]. Mechanistically, increased perineurial iNOS expression and alterations in gap junction proteins could further contribute to BNB destabilization in addition to reduced claudin-1 [33].

Cldn1 and Cldn5 in the nerve have been extensively studied in traumatic nerve injury. So, what could be the mechanisms underlying reduced Cldn 1 in the perineurium and Cldn5 in microvessels as well as loss of vessel-associated macrophages in the endoneurium impairing the BNB function? Cldn1 is regulated by the wnt pathway [22], metalloproteinases, and low-density lipoprotein receptor-related protein1 [42], as well as microRNA (miR)-155 [12], miR-21, and miR-183 [43]. Cldn5 and Tjp1 are regulated by the sonic hedgehog pathway in Lepr $^{\mathrm{db} / \mathrm{db}}$ type 2 diabetic mice and after nerve injury $[10,18]$. Moreover, restoration of blood vesselassociated macrophages could reinstate endothelial barrier function. As activating the sonic hedgehog pathway restores endothelial barrier function in diabetic neuropathy [44], thus, not only tight junction proteins, but also recruitment of macrophages and pericytes could be regulated by common pathways. In summary, treatment with, e.g., glycogen-synthasekinase-3 $\beta$ inhibitors [22, 45], miR-155 antagomirs [46], or hedgehog fusion proteins [47] could promote BNB sealing in DPN. Some of these inhibitors are currently under investigation for diabetes treatment $[15,47,48]$.
DPN is not usually categorized as an immune-mediated neuropathy; however, microvascular changes could be induced by the inflammatory cascades. In our study, we did not observe any increased macrophage infiltration 8 weeks after injection in line with previous studies [49]. Macrophage infiltration is reduced 2-3 weeks in the sciatic nerve after STZ application in mice but return to normal after 13 weeks [50]. Depleting macrophages after STZ injection delayed neuropathic pain onset [51]. Besides their harmful role in pain pathways, macrophages are also known for their beneficial properties following nerve injury. In our study, we found a vessel-associated macrophage loss. In $D h h^{-/}$mice-which also have leaky endoneurial capillaries-M2 macrophages produce vascular endothelial growth factor-A [18]. Macrophage depletion normalized

Fig. 7 Decreased claudin-1 immunoreactivity in the perineurium and vessel-associated macrophages in prolonged STZ DPN. Sciatic nerve from male Wistar rats was stained with anti-claudin-1 (a, b), anticlaudin-5 + anti-von Willebrand factor (vWF, c, d). Claudin-5 was quantified relative to $\beta$-actin by Western blot (e). Vessel-associated macrophages were identified by immunolabeling with anti-CD68 and anti-vWF (f, g) or anti-CD206 and RECA-1 (h, i). Fluorescence intensity was quantified in the regions of interest (perineurium; a, b) and (vWF+ vessels; c, d) normalized to the area. $\mathbf{f}, \mathbf{g}, \mathbf{h}, \mathbf{i}$ The total number of macrophages (CD68+ or CD206+) in proximity to blood vessels (vWF+ or RECA-1+) was counted and expressed relative to the total number of capillaries in the endoneurium. $n=5-6$. Arrows depict examples. Scale bars $=100 \mu \mathrm{m}$ and in the insert $20 \mu \mathrm{m}(\mathbf{f}, \mathbf{g})$ and $10 \mu \mathrm{m}(\mathbf{h}, \mathbf{i})$, dot plots represent medians and interquartile range, Mann-Whitney test for comparison. $* P<0.05$ and $* * P<0.01$ 


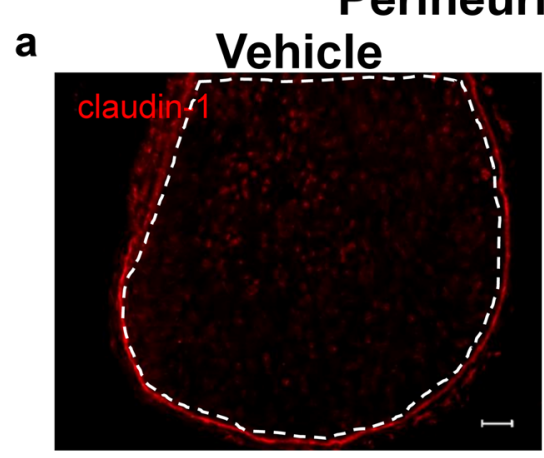

\section{Perineurial barrier}
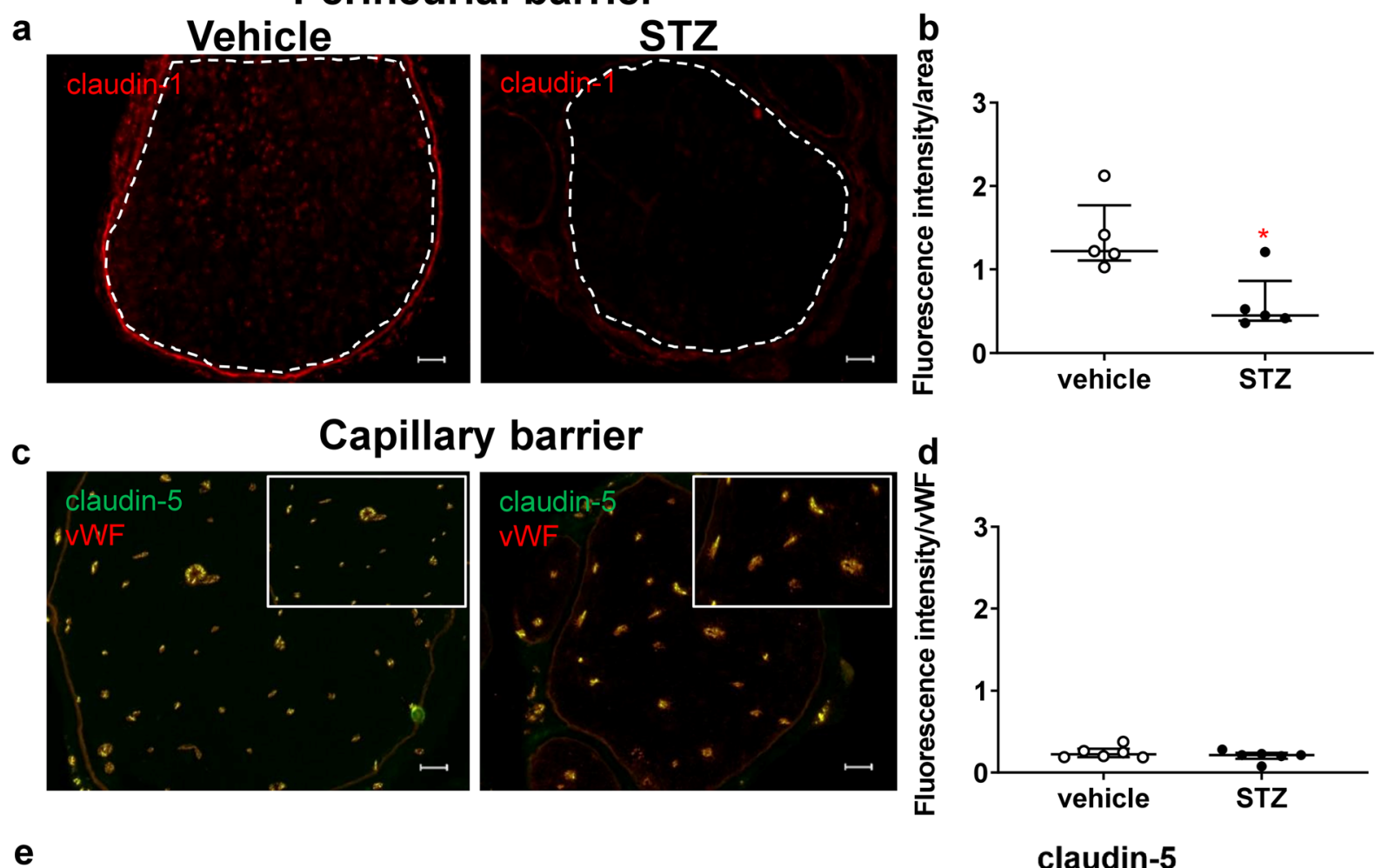

e
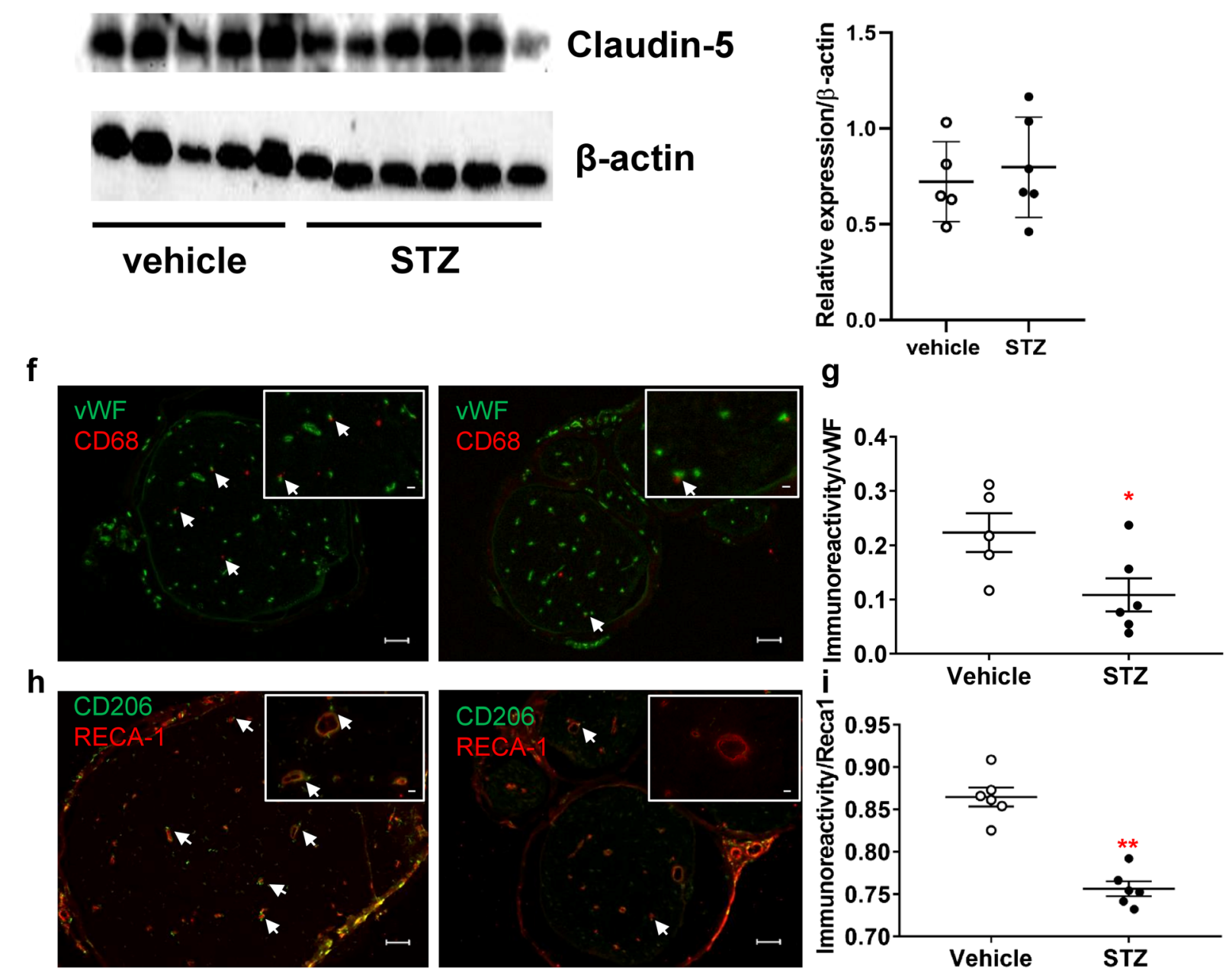
capillary density and lumen. Since neither leakiness in $D h h^{-/-}$ nor macrophages/neuroinflammation in diabetic $L e p r^{\mathrm{db} / \mathrm{db}}$ were evaluated, the role of macrophages for barrier stability was not clarified. Perivascular macrophages are found in many organs and play an important role: they maintain tight junctions, limit capillary permeability and inappropriate inflammation and phagocytose material in the brain, kidney, heart, lung, skin, etc. [52]. Malong and colleagues have shown that vesselassociated macrophages are necessary in order to preserve blood-nerve barrier integrity: tamoxifen-treated P0-RafTR mice have a leaky capillary barrier with normal tight junction protein expression but enhanced transcytosis and reduced numbers of vessel-associated macrophages [13]. This points to a novel beneficial rather than harmful macrophage role at the BNB, which might depend on the macrophage subtype, anatomical location, and disease state. For example, antiinflammatory or vessel-associated macrophages could promote pain resolution.

Barrier leakiness in STZ-induced diabetes is selective for small molecules potentially facilitating edema formation and proalgesic mediator leakage (summarized in [53]). In diabetic patients, this could explain previous findings: (1) nerve edema observed, e.g., by T2 mapping in MRI neurography in patients with DPN [54], (2) altered tight junctions in DPN [19], and (3) altered BNB permeability to blood-borne proteins like glycosylated albumin [55]. Most studies were conducted in type 2 diabetes necessitating more studies in type 2 diabetes models or type 1 diabetic patients. In summary, our data argue that small molecule BNB leakiness is responsible for DPN perpetuation and further nerve destruction rather than an inciting event. This is in sharp contrast to very early BNB changes in nerve injury where barrier leakiness to both small and macromolecules increases and precedes hypersensitivity [12].

\begin{abstract}
Abbreviations BNB, Blood-nerve barrier; DPN, Diabetic polyneuropathy; EBA, Evans blue albumin; LMD, Laser-assisted microdissection; NaFlu, Sodium fluorescein; STZ, Streptozotocin; TJP1, Tight junction protein 1 ; ZO-1, Zonula occludens protein 1
\end{abstract}

Supplementary Information The online version contains supplementary material available at https://doi.org/10.1007/s00109-021-02091-1.

Author contribution This study was designed by H.L.R., R.S.S., A.B., and K.D. Experiments were performed by A.B-K., R.S.S., C.N., M.P., A.L.B., and M.S.A. R.B. helped to establish laser-assisted microdissection. H.L.R. and A.B-K. wrote the paper. H.L.R. supervised the project. A.B-K., R.S.S., C.N., M.P., A.L.B., M.S.A., A.B., R.B., K.D., and H.L.R. participated in data interpretation and revising the paper and approved the final version of the manuscript. H.L.R. is the guarantor of this work and, as such, had full access to all of the data in the study and takes responsibility for the integrity of the data and the accuracy of the data analysis.

Funding Open Access funding enabled and organized by Projekt DEAL. This study was supported by funds from the University Hospital of Würzburg, the Graduate School of Life Sciences (C.N. and M.P.), the
Interdisciplinary Center of Clinical Research Würzburg (R.B. and H.L.R.: N-D-368), and the Evangelisches Studienwerk Villigst (A.BK.). R.S.S. was supported by the German Research Foundation (H.L.R.: Ri 817/13-1).

Data availability The data supporting the findings of this study are available upon request to the authors.

\section{Declarations}

Ethics Animal protocols (\# REG 2-264) have been approved by the animal care committee of the provincial government of Würzburg. Handling procedures were in accordance with international guidelines for the care and use of laboratory animals (EU Directive 2010/63/EU for animal experiments). Score sheets with defined end points were used daily to monitor animal well-being. All details are mentioned in the research design and methods segment of the paper.

Open Access This article is licensed under a Creative Commons Attribution 4.0 International License, which permits use, sharing, adaptation, distribution and reproduction in any medium or format, as long as you give appropriate credit to the original author(s) and the source, provide a link to the Creative Commons licence, and indicate if changes were made. The images or other third party material in this article are included in the article's Creative Commons licence, unless indicated otherwise in a credit line to the material. If material is not included in the article's Creative Commons licence and your intended use is not permitted by statutory regulation or exceeds the permitted use, you will need to obtain permission directly from the copyright holder. To view a copy of this licence, visit http://creativecommons.org/licenses/by/4.0/.

\section{References}

1. Raputova J, Srotova I, Vlckova E, Sommer C, Uceyler N, Birklein F, Rittner HL, Rebhorn C, Adamova B, Kovalova I, Kralickova Nekvapilova E, Forer L, Belobradkova J, Olsovsky J, Weber P, Dusek L, Jarkovsky J, Bednarik J (2017) Sensory phenotype and risk factors for painful diabetic neuropathy: a cross-sectional observational study. Pain 158(12):2340-2353

2. Finnerup NB, Attal N, Haroutounian S, McNicol E, Baron R, Dworkin RH, Gilron I, Haanpaa M, Hansson P, Jensen TS, Kamerman PR, Lund K, Moore A, Raja SN, Rice AS, Rowbotham M, Sena E, Siddall P, Smith BH, Wallace M (2015) Pharmacotherapy for neuropathic pain in adults: a systematic review and meta-analysis. Lancet Neurol 14(2):162-173

3. van Hecke O, Austin SK, Khan RA, Smith BH, Torrance N (2014) Neuropathic pain in the general population: a systematic review of epidemiological studies. Pain 155(4):654-662

4. Richner M, Ferreira N, Dudele A, Jensen TS, Vaegter CB, Goncalves NP (2018) Functional and structural changes of the blood-nerve-barrier in diabetic neuropathy. Front Neurosci 12: 1038

5. Doppler K, Frank F, Koschker AC, Reiners K, Sommer C (2017) Nodes of Ranvier in skin biopsies of patients with diabetes mellitus. J Peripher Nerv Syst 22(3):182-190

6. Karlsson P, Provitera V, Caporaso G, Stancanelli A, Saltalamacchia AM, Borreca I, Manganelli F, Santoro L, Jensen TS, Nolano M (2021) Increased peptidergic fibers as a potential cutaneous marker of pain in diabetic small fiber neuropathy. Pain 162(3):778-786

7. Reinhold AK, Rittner HL (2020) Characteristics of the nerve barrier and the blood dorsal root ganglion barrier in health and disease. Exp Neurol 327:113244 
8. Hackel D, Krug SM, Sauer RS, Mousa SA, Bocker A, Pflucke D, Wrede EJ, Kistner K, Hoffmann T, Niedermirtl B, Sommer C, Bloch L, Huber O, Blasig IE, Amasheh S, Reeh PW, Fromm M, Brack A, Rittner HL (2012) Transient opening of the perineurial barrier for analgesic drug delivery. Proc Natl Acad Sci U S A 109(29):E2018-E2027

9. Lim TKY, Shi XQ, Martin HC, Huang H, Luheshi G, Rivest S, Zhang J (2014) Blood-nerve barrier dysfunction contributes to the generation of neuropathic pain and allows targeting of injured nerves for pain relief. Pain 155(5):954-967

10. Moreau N, Mauborgne A, Bourgoin S, Couraud PO, Romero IA, Weksler BB, Villanueva L, Pohl M, Boucher Y (2016) Early alterations of Hedgehog signaling pathway in vascular endothelial cells after peripheral nerve injury elicit blood-nerve barrier disruption, nerve inflammation, and neuropathic pain development. Pain 157(4):827-839

11. Reinhold AK, Schwabe J, Lux TJ, Salvador E, Rittner HL (2018) Quantitative and microstructural changes of the blood-nerve barrier in peripheral neuropathy. Front Neurosci 12:936

12. Reinhold AK, Yang S, Chen JT, Hu L, Sauer RS, Krug SM, Mambretti EM, Fromm M, Brack A, Rittner HL (2019) Tissue plasminogen activator and neuropathy open the blood-nerve barrier with upregulation of microRNA-155-5p in male rats. Biochim Biophys Acta Mol basis Dis 1865(6):1160-1169

13. L. Malong, I. Napoli, I.J. White, Stierli S., A. Bossio, A.C. Lloyd, Macrophages enforce the blood nerve barrier, bioRx (2020).

14. Sauer RS, Kirchner J, Yang S, Hu L, Leinders M, Sommer C, Brack A, Rittner HL (2017) Blood-spinal cord barrier breakdown and pericyte deficiency in peripheral neuropathy. Ann N Y Acad Sci 1405(1):71-88

15. Lux TJ, Hu X, Ben-Kraiem A, Blum R, Chen JT, Rittner HL (2019) Regional differences in tight junction protein expression in the blood-DRG barrier and their alterations after nerve traumatic injury in rats. Int J Mol Sci 21(1)

16. Shimizu F, Sano Y, Haruki H, Kanda T (2011) Advanced glycation end-products induce basement membrane hypertrophy in endoneurial microvessels and disrupt the blood-nerve barrier by stimulating the release of TGF-beta and vascular endothelial growth factor (VEGF) by pericytes. Diabetologia 54(6):1517-1526

17. Rechthand E, Smith QR, Latker CH, Rapoport SI (1987) Altered blood-nerve barrier permeability to small molecules in experimental diabetes mellitus. J Neuropathol Exp Neurol 46(3):302-314

18. Chapouly C, Yao Q, Vandierdonck S, Larrieu-Lahargue F, Mariani JN, Gadeau AP, Renault MA (2016) Impaired Hedgehog signalling-induced endothelial dysfunction is sufficient to induce neuropathy: implication in diabetes. Cardiovasc Res 109(2):217227

19. Beamish NG, Stolinski C, Thomas PK, King RH (1991) Freezefracture observations on normal and abnormal human perineurial tight junctions: alterations in diabetic polyneuropathy. Acta Neuropathol 81(3):269-279

20. Hill RE, Williams PE (2004) Perineurial cell basement membrane thickening and myelinated nerve fibre loss in diabetic and nondiabetic peripheral nerve. J Neurol Sci 217(2):157-163

21. King AJ (2012) The use of animal models in diabetes research. $\mathrm{Br} \mathrm{J}$ Pharmacol 166(3):877-894

22. Sauer RS, Krug SM, Hackel D, Staat C, Konasin N, Yang S, Niedermirtl B, Bosten J, Gunther R, Dabrowski S, Doppler K, Sommer C, Blasig IE, Brack A, Rittner HL (2014) Safety, efficacy, and molecular mechanism of claudin-1-specific peptides to enhance blood-nerve-barrier permeability. J Control Release 185: 88-98

23. Deuis JR, Dvorakova LS, Vetter I (2017) Methods used to evaluate pain behaviors in rodents. Front Mol Neurosci 10:284
24. Hackel D, Brack A, Fromm M, Rittner HL (2012) Modulation of tight junction proteins in the perineurium for regional pain control. Ann N Y Acad Sci 1257(1):199-206

25. Fox A, Eastwood C, Gentry C, Manning D, Urban L (1999) Critical evaluation of the streptozotocin model of painful diabetic neuropathy in the rat. Pain 81(3):307-316

26. Schulzke JD, Ploeger S, Amasheh M, Fromm A, Zeissig S, Troeger H, Richter J, Bojarski C, Schumann M, Fromm M (2009) Epithelial tight junctions in intestinal inflammation. Ann N Y Acad Sci 1165: 294-300

27. Koizumi T, Kerkhofs D, Mizuno T, Steinbusch HWM, Foulquier S (2019) Vessel-associated immune cells in cerebrovascular diseases: from perivascular macrophages to vessel-associated microglia. Front Neurosci 13:1291

28. Cattin AL, Burden JJ, Van Emmenis L, Mackenzie FE, Hoving JJ, Garcia Calavia N, Guo Y, McLaughlin M, Rosenberg LH, Quereda V, Jamecna D, Napoli I, Parrinello S, Enver T, Ruhrberg C, Lloyd AC (2015) Macrophage-induced blood vessels guide Schwann cellmediated regeneration of peripheral nerves. Cell 162(5):1127-1139

29. Wang D, Zhang X, Lu L, Li H, Zhang F, Chen Y, Shen J (2015) Assessment of diabetic peripheral neuropathy in streptozotocininduced diabetic rats with magnetic resonance imaging. Eur Radiol 25(2):463-471

30. Schwarz D, Hidmark AS, Sturm V, Fischer M, Milford D, Hausser I, Sahm F, Breckwoldt MO, Agarwal N, Kuner R, Bendszus M, Nawroth PP, Heiland S, Fleming T (2020) Characterization of experimental diabetic neuropathy using multicontrast magnetic resonance neurography at ultra high field strength. Sci Rep 10(1):7593

31. Seneviratne KN (1972) Permeability of blood nerve barriers in the diabetic rat. J Neurol Neurosurg Psychiatry 35(2):156-162

32. Nitta T, Hata M, Gotoh S, Seo Y, Sasaki H, Hashimoto N, Furuse M, Tsukita S (2003) Size-selective loosening of the blood-brain barrier in claudin-5-deficient mice. J Cell Biol 161(3):653-660

33. Pitre DA, Seifert JL, Bauer JA (2001) Perineurium inflammation and altered connexin isoform expression in a rat model of diabetes related peripheral neuropathy. Neurosci Lett 303(1):67-71

34. Rom S, Heldt NA, Gajghate S, Seliga A, Reichenbach NL, Persidsky Y (2020) Hyperglycemia and advanced glycation end products disrupt BBB and promote occludin and claudin-5 protein secretion on extracellular microvesicles. Sci Rep 10(1):7274

35. Geng J, Wang L, Zhang L, Qin C, Song Y, Ma Y, Chen Y, Chen S, Wang Y, Zhang Z, Yang GY (2018) Blood-brain barrier disruption induced cognitive impairment is associated with increase of inflammatory cytokine. Front Aging Neurosci 10:129

36. Montague-Cardoso K, Pitcher T, Chisolm K, Salera G, Lindstrom E, Hewitt E, Solito E, Malcangio M (2020) Changes in vascular permeability in the spinal cord contribute to chemotherapy-induced neuropathic pain. Brain Behav Immun 83:248-259

37. Goncalves NP, Vaegter CB, Andersen H, Ostergaard L, Calcutt NA, Jensen TS (2017) Schwann cell interactions with axons and microvessels in diabetic neuropathy. Nat Rev Neurol 13(3):135147

38. Zuvic-Butorac M, Kriz J, Simonic A, Schara M (2001) Fluidity of the myelin sheath in the peripheral nerves of diabetic rats. Biochim Biophys Acta 1537(2):110-116

39. Bierhaus A, Fleming T, Stoyanov S, Leffler A, Babes A, Neacsu C, Sauer SK, Eberhardt M, Schnolzer M, Lasitschka F, Neuhuber WL, Kichko TI, Konrade I, Elvert R, Mier W, Pirags V, Lukic IK, Morcos M, Dehmer T, Rabbani N, Thornalley PJ, Edelstein D, Nau C, Forbes J, Humpert PM, Schwaninger M, Ziegler D, Stern DM, Cooper ME, Haberkorn U, Brownlee M, Reeh PW, Nawroth PP (2012) Methylglyoxal modification of Nav1.8 facilitates nociceptive neuron firing and causes hyperalgesia in diabetic neuropathy. Nat Med 18(6):926-933

40. Eberhardt MJ, Filipovic MR, Leffler A, de la Roche J, Kistner K, Fischer MJ, Fleming T, Zimmermann K, Ivanovic-Burmazovic I, 
Nawroth PP, Bierhaus A, Reeh PW, Sauer SK (2012) Methylglyoxal activates nociceptors through transient receptor potential channel A1 (TRPA1): a possible mechanism of metabolic neuropathies. J Biol Chem 287(34):28291-28306

41. Dull MM, Riegel K, Tappenbeck J, Ries V, Strupf M, Fleming T, Sauer SK, Namer B (2019) Methylglyoxal causes pain and hyperalgesia in human through C-fiber activation. Pain 160(11): 2497-2507

42. Zwanziger D, Hackel D, Staat C, Bocker A, Brack A, Beyermann M, Rittner H, Blasig IE (2012) A peptidomimetic tight junction modulator to improve regional analgesia. Mol Pharm 9(6):17851794

43. Yang S, Krug SM, Heitmann J, Hu L, Reinhold AK, Sauer S, Bosten J, Sommer C, Fromm M, Brack A, Rittner HL (2016) Analgesic drug delivery via recombinant tissue plasminogen activator and microRNA-183-triggered opening of the blood-nerve barrier. Biomaterials 82:20-33

44. Kusano KF, Allendoerfer KL, Munger W, Pola R, Bosch-Marce M, Kirchmair R, Yoon YS, Curry C, Silver M, Kearney M, Asahara T, Losordo DW (2004) Sonic hedgehog induces arteriogenesis in diabetic vasa nervorum and restores function in diabetic neuropathy. Arterioscler Thromb Vasc Biol 24(11):2102-2107

45. Ramirez SH, Fan S, Dykstra H, Rom S, Mercer A, Reichenbach NL, Gofman L, Persidsky Y (2013) Inhibition of glycogen synthase kinase 3 beta promotes tight junction stability in brain endothelial cells by half-life extension of occludin and claudin-5. PLoS One 8(2):e55972

46. Chen J, Li C, Liu W, Yan B, Hu X, Yang F (2019) miRNA-155 silencing reduces sciatic nerve injury in diabetic peripheral neuropathy. J Mol Endocrinol 63(3):227-238

47. Calcutt NA, Allendoerfer KL, Mizisin AP, Middlemas A, Freshwater JD, Burgers M, Ranciato R, Delcroix JD, Taylor FR, Shapiro R, Strauch K, Dudek H, Engber TM, Galdes A, Rubin LL, Tomlinson DR (2003) Therapeutic efficacy of sonic hedgehog protein in experimental diabetic neuropathy. J Clin Invest 111(4): 507-514

48. MacAulay K, Woodgett JR (2008) Targeting glycogen synthase kinase-3 (GSK-3) in the treatment of type 2 diabetes. Expert Opin Ther Targets 12(10):1265-1274

49. Conti G, Scarpini E, Baron P, Livraghi S, Tiriticco M, Bianchi R, Vedeler C, Scarlato G (2002) Macrophage infiltration and death in the nerve during the early phases of experimental diabetic neuropathy: a process concomitant with endoneurial induction of IL-1 beta and p75NTR. J Neurol Sci 195(1):35-40

50. Hidmark AS, Nawroth PP, Fleming T (2017) STZ causes depletion of immune cells in sciatic nerve and dorsal root ganglion in experimental diabetes. J Neuroimmunol 306:76-82

51. Mert T, Gunay I, Ocal I, Guzel AI, Inal TC, Sencar L, Polat S (2009) Macrophage depletion delays progression of neuropathic pain in diabetic animals. Naunyn Schmiedeberg's Arch Pharmacol 379(5):445-452

52. Lapenna A, De Palma M, Lewis CE (2018) Perivascular macrophages in health and disease. Nat Rev Immunol 18(11):689-702

53. Mizisin AP (2014) Mechanisms of diabetic neuropathy: Schwann cells. Handb Clin Neurol 126:401-428

54. Wang D, Wang C, Duan X, Yang Z, Bai Z, Hu H, Yan L, Shen J (2018) MR T2 value of the tibial nerve can be used as a potential non-invasive and quantitative biomarker for the diagnosis of diabetic peripheral neuropathy. Eur Radiol 28(3):1234-1241

55. Poduslo JF, Curran GL (1992) Increased permeability across the blood-nerve barrier of albumin glycated in vitro and in vivo from patients with diabetic polyneuropathy. Proc Natl Acad Sci U S A 89(6):2218-2222

Publisher's note Springer Nature remains neutral with regard to jurisdictional claims in published maps and institutional affiliations. 